\title{
Research on Mobile Music Industry Chain Based on Value Innovation
}

\author{
Lin $\mathrm{Yu}$ \\ College of Music ,Jiangxi University of Technology
}

Keywords: Mobile music; Industry chain; Value innovation; Industry cooperation

\begin{abstract}
With the traditional music becoming more and more atrophied,mobile music has attracted wide attention in the industry the moment it is released-the traditional music industry regards it as a life-saving straw,and operators also regard it as one of the most profitable businesses. The success of mobile music on the one hand is due to the fact that it wonderfully captures the current consumers requirements on mobility and individuation,providing good user experience for consumers. On the other hand it has many innovations in the construction of Industry chain and the operation patterns of industry chain.Mobile music in our country has been developing so quickly since it was released, at present the industry chain has initially come into being,but the main bodies of industry chain are all eager to sut up their own brands and compete for more users because of lacking clear market leadeds.In comparison with international advanced operators especially In comparison with the development of Japanese and South Korean mobile music,there are obvious deficiencies in Tracking and mining user needs in domestic businesses,and there also exists a certain gap in Industry chain construction, profit patterns, industry chain cooperation and supervision.Finally we deeply study the existing problems of mobile music in our country and offer corresponding suggestions by analyzing the development of mobile music markets in our country and the present situation in industry chain and then comparing with Japanese and South Korean operators.
\end{abstract}

\section{Introduction}

According to the statistical bulletin of communication industry released by Ministry of information industry in 2007, national mobile phone users newly increased 8622.8, reaching to 54728.6.2007 is the year in which mobile phone users increase most,and the mobile phone popularity rate reaches to 41.6 per 100 people. The mobile communication in our country has formed a considerable scale based on the past 20 years rapid development, with the customer popularity rate rising, market saturation will further increase, and the phenomenon that products and services of mobile communication homogenizes will be more and more serious,leading to a situation of "supplies can't meet needs".In this condition, mobile music is expected too much.At the same time,traditional recording industry has suffered huge economic losses because of the largely exist of illegally shared music on the Internet,so they urgently need to find out a new type and secure transmission mode, and mobile music rightly offers them an ideal choice depending on its security and great spreadability.

As the technology progresses and users' demands are further stimulated,all parties in mobile music industry chain will go hand in hand with each other.With matched music mobile phones,mobile music strives for the settlement of Whole song download and other high-speed data businesses;Music mobile phones need to accelerate the penetration of the low-end markets with the help of mobile businesses;Content providers, such as recording companies are in great need of mobile 
music- a life-saving straw.Operators as well need mobile music which has great market prospects to help attract consumers.All kind of factors urge the role of industry chain and the relationship between different main bodies to vary correspondingly,meanwhile,the operation mode of industry chain will reforms.

\section{Mobile musical aspects analyses}

At present mobile music industry chain mainly consists of content providers, service providers,operators,mobile music users and terminal equipment manufacturers. While strengthening the control of contents,Operators also work closely with handset makers,making Customized or semi- Customized mobile phones very popular.The cooperation in capital and technology between operators and handset makers not only help largely decrease production costs,but also is helpful to design features which are suitable for consumers' demands in the terminal,making it convenient,easy to use and attractive.

As the last link of mobile music content delivery process,mobile music users play the role of paying for music products and sevices in mobile environment. From the perspective of income,we can see that the money which users spend on music products and sevices is distributed to the kinds of links in industry chain,of course,the specific allotment method is opaque to users, and in fact users do not care about it.Users' characteristics demands are different as may factors,such as age,gender, region,income vary, and we will not have a more specific users analysis here.Obviously,in the present time when piracies are so rampant,mobile music users hope to get convenient,interesting and high quality products and services with reasonable price.And this is also the point which the manufacturers in various links of mobile music industry chain should pay attention to.In such an industry chin full of huge potential,the relationship between the members in various links is complex,and there exists cooperation contradictions and mutual benefits of the win-win.

The vigorous development of mobile music makes the parties in industry chain hope to continuously expand themselves to get some shares.Right now,content providers are beginning to make mobile music contents, and directly cooperate with operators, bypassing SP to provide them for users.Operators also cooperate with record companies, and they gradually start to play the role of SP. Terminal manufacturers have also joined the melee,and iphone,Nokia both show great interest in it,moreover,the business model of iphone even fundamentally overturns the industry chain operation which was dominated by operators for a long time.

Within the industry of mobile music,content providers,mobile operators and service providers each have different resource advantages.Content providers provide music products and services,mobile operators provide universal access means and secure technical support,and service providers provide users with the top contents and application.As long as the division of labor is reasonable,they will exert their own resource advantages.In fact,mobile music businesses can bring many commom benefits for all the participants in industry chain,realizing win-win of industry chain.

First of all,mobile music can help operators solve the prominent contradictions that the number of users increases, but the value ofARI,U declines.The world-leading operators are all focusing on young fashion groups, who are the main force of $3 \mathrm{G}$ business. it'sfair to say that the interests of the operators and content providers are highly consistent in terms of user groups.

Moreover,the prosperity of mobile music business has made the service providers grow stronger and stronger,and the continuously increasing service contents will greatly increase the business volume of the operators, the business income of the operators will also greatly increase.By mobile 
music, operators can not only increase the income of the data business, but the more important point is to improve the user viscosity and loyalty.

Finally, that content providers and mobile operators create a perfect mobile music industry chain will be helpful to their own brand construction and upgrade, and the value of potential commom brands is very huge. In the study, many scholars also compare value innovation with strategy innovation. Hamel (1998) defined strategy innovation as creating a new value method for customers to redesign the industry model,making competitors be too late to do anything about it and creating new wealth for all shareholders.M and Mauborgne (1999) proposed that by offering completely new, better customer value to compete for nothing, and to create new markets through the leap promotion of customer value. C Li Stensen et al (2002) also proposed to create a high growth of enterprises by creating new markets and new ways of competition. The above sayings all include two aspects:the delivery of more value for customers - customer value innovation and the redefinition of markets and industry boundaries - value of the industry chain innovation.

With the development of economy, the demands of customer are also deepened constantly, and according to Maslow's theory of hierarchy of needs, the rapid development of society has made the majority of users more intensely pursue personalities and vent their personalities,in this condition, Personalized products and services are becoming more and more popular with users. Customer value innovation theory believes that enterprises should not be limited to the scope of existing resources, but should always regard customer demands as the center, as long as there are opportunities of creating new customer value, enterprises ought to break the limitation of industry, guide industries to develop towards the direction of contributing to creating customer value, which can also create profits for the industry chain parties.

In brief, to enterprises, a customer is a kind of valuable resources, only by constantly improving customers' delivered value, winning high value customers,can the entire value chain profits continuously improve and it also help enterprises realize profits maximization. The core of value innovation theory is customer value innovation, the ultimate goal of value innovation is to provide new and unprecedented products and services for customers, and to provide value innovation for customers is also associated with the transformation of the industry chain. As a new musical form different from past traditional music,mobile music shows its enormous potential as soon as it is released. Tone, ring back tone,whole song download......these music products which has never occurred in the past nicely meet the needs of consumers, of course, we can also see the mobile music industry chain has quickly made preparation for this from all sides, it is fair to say that the success of mobile music is closely related to the value innovation of the whole industry chain. With the deepening of economic development, consumers' consumption concepts are constantly changing as their living standards improve. To the parties of industrial chain, they should not only to pay close attention to changes in consumers' demands, keeping up with consumers' demands at any time,the more important thing is to sharply capture customers' potential demands, always transcend and continue to create customer value.

With the emergence of new businesses, the role of the industry chain is also changing, a number of new companies come into being following the new businesses.In terms of mobile music industry chain, ring tones, tone and other new businesses have also spawned a new a group of specialized music service providers. At the same time, with the challenge of mobile music and other digital music to traditional music becoming stronger and stronger and piracy constantly improving, the whole industry chain attaches great importance to copyright to an unprecedented degree, for example, 
the source of Intellectual Property Agency Co., Ltd. is produced under this situation. The ultimate goal of every role in the industry chain is to create customer value, improve the value distribution of customers in the whole industry chain. With the increase of new businesses, the division of labor in industry chain is increasingly clear, and the relationship between the parties of the industry chain is also more complex. The traditional value theory lays more emphases on competition,for example,the Positioning school, the Core Capacity School all emphasize to obtain the scarce resources through differentiation, thus winning the competitive advantages for enterprises. The value innovation theory emphasizes the new organization form in which customers are the center,and it distributes interests based on the value preference and value structure of different subjects. The rational distribution of the output mode is conducive to stimulate the initiative of all the main bodies, making the operation of the whole industry chain more smooth.As for the mobile music industry chain, the main bodies in industry chain are also seeking to penetrate each other. Operators expect to bypass the SP and directly cooperate with $\mathrm{CP}$, at present, the several major operators have already launched cooperations with record companies; Terminal manufacturers are trying to build their own music portals and music brands, and NOKIA, Sony Ericsson and so on also expect to get some shares in mobile music. The relationship between the participants makes the mobile music industry chain gradually develop into the problem that under the complex division of information technology revolution, the information asymmetry among enterprises is becoming more and more serious, and it is not easy to coordinate Simply relying on enterprises or markets, so a more efficient mechanism must be designed to promote the harmonious development of the industry. Now we will combine the industry collaboration theory to discuss what synergy patterns the mobile music industry chain should take for better value innovation. In this place we will mainly discuss the value net of the cooperation mode between operators and music product providers instead of the traditional simple chain structure.

In the field of mobile music a very difficult problem is piracy,and rampant piracy gives a severe blow to the content providers especially the enthusiasm of record companies, and the lack of good music content is bound to cause the further vicious circle in the whole industry chain, Japan is a good case in the protection of music copyright.

From the above analysis, we can see the success of Japanese mobile music lies in three main factors:

First, focusing on providing users with personalized and mobile products and services. Under the premise of creating profits, personalization and mobility is the important trend.It can be said that personalization is the key to creating differentiated services, while mobility makes products and services contact users anytime and anywhere through mobile phone terminals, thus they will really have opportunities to charge the final users.

Second,establishing a profit model which is conducive to the win-win of industry chain. From the value chain of "Melon", SKT plays the role of operators and service providers. It can be said that the smooth running of "Melon" service is based on the mutual trust relationship between SKT and content providers.

Third,the perfection of industry chain, close cooperation and the same target.Besides signing a licensing agreement with record companies, SKTeleeom also actively move forward through investing media companies and setting up joint ventures,and they also invest music fund to further grasp the source of music and stimulate the development of music industry. 
Mobile music in our country has experienced rapid development in recent years, but we can also see that the various links in industry chain have not yet integrated into an organic whole.The industry chain has initially formed, but with the penetration of operators to upstream and downstream, SP, CP mutual convergence and terminal manufacturers' seeking greater market space, the entire industry pattern is bound to change greatly,and this also requires a more reasonable profit sharing as well as the industry chain operation mode to protect the lasting innovation and healthy development of the entire mobile music industry chain.Based on the analysis of mobile music market development and industry chain composition and operation mode, we will compare the conditions of operators in our country with those in South Korea and Japan,expecting to learn from it.

Firstly, in terms of the sharing mode,two years ago, the distribution mode of mobile music was mainly: operators share 15\%,SP companys share $85 \%$, and then SP companies give CP companies under - plus share according to the cooperation conditions between them.A very practical problem is that the information asymmetry of various commercial organizations during the process of cooperations and trades,SP conceals settlement income in the process of settling accounts with copyrights, and delays the settlement time, but all the right people, including telecom operators, $\mathrm{CP}$, don't know SP download quantity and real income, unable to realize reasonable sharing mechanism. Information asymmetry objectively caused two awkward situations:record companies does not trust SP, and they still tend to issue through traditional channels, resulting in high freights;SP worries about they may not have enough to eat,and transfers cost onto consumers in other ways, improving the consumers purchase costs, thereby affecting the sales, giving rise to vicious cycle,impacting the patency and the positive cycle of value chain.Now with the fading of large number of SP companies, some mainstream CP companies begin to wear the double identity of $\mathrm{CP}$ and SP, and when $\mathrm{CP}$ directly cooperates with operators, profit distribution ratio can usually reach to 5:5,so the attraction is obvious.

However, the change of the role does not mean that cooperation can become easier. For both sides of the cooperation, the promotion cost of songs is an important link between the two sides."In this seemingly simple chain, the division of each role is not clear". Who should conduct the promotion and marketing of music?How much should be spent? These are both urgent problems to be solved. Secondly, the protection of intellectual property rights in China is deficient,and the awareness of protection of intellectual property is not in the place either to the law or to ordinary users. From the perspective of the entire industry chain of mobile music, at present record companies mostly adopt the the cooperation mode of one-time buyout for a song,and they Frequently offer price of 10 million,but these singles may not be popular in the network and wireless markets in the future, which makes the risk over focus on small and medium SP,and increases the market risk of the latter. Small and medium record companies are busy to explore singers, packaging and performances and so on due to limited strength,putting their main energy on creation, and They do not know how to monitor wireless environment and how to combat piracy.Record companies and SP cannot achieve risk sharing and benefit sharing.Specifically,the copyright protection of the music is mainly facing two major challenges.The first one is that Authorization identification is so complex. From the classification of the right, there are copyright, intellectual copyright, link rights, etc., and related rights are sometimes shared by several companies, sometimes are changed, and are repeatedly authorized.It is very complicated to confirm the rights of Songwriters, performers and record companies.The second thing is the lack of transparent and standardized fees statistics,clearing platforms and mechanisms between right holders and various commercial organizations. The lack of 
powerful music copyright protection mechanism can also make music creators have no enough power to create more better music works, and the lack of contents is bound to affect the effective functioning of industry chain from a long-term perspective.

The value innovation of mobile music needs the joint efforts of all parties in industry chain,and it is essential to establish operation mode conducive to win-win of industry chain,to build a complete industry chain which has consistent goal, close cooperation and to meet the deeper and personalized demands of consumers.

\section{Conclusions}

In this thesis, the industry chain and value chain theory are introduced to the analysis of the development of mobile music, as a breakthrough direction of research. After the analysis of the mobile music and the market development of related industries, it detailedly study the composition of the mobile music industry chain and the relationship between the main bodies.It analyses how to realize the value innovation of industry chain in mobile music from the role of chain and the reconstruction of value chain, industry chain operation mode and the related relationship among the main bodies of the industry chain. Meanwhile,considering the fact that Japanese and Korean operators are in leading position in data business, This thesis takes KDDI and SKTelecom as examples to analyze how the two realize value innovation of mobile music industry chain. After reviewing and analyzing the development of mobile music in China and the market segments, the thesis analyzes the status of the chain structure, the operation pattern and the relationship among the main bodies of mobile music industry. Through the comparison with Japan and South Korea,the existing problems of mobile music in China are further analyzed and some suggestions are given.It is hoped that it can provide references for the development and value innovation of mobile music in our country.

\section{References}

[1] the Ministry of information industry of the people's Republic of China 2007 National Communications Development Statistics Bulletin February 2008

Http://www.mii.gov.cn/art/2008/03/25/art_169_36s79.html

[2]Ari Market Consulting Co., Ltd. China Mobile Music Research Report 2007 Jane 2007 Page 4-5

[3]Ari Marketing Consulting Co., Ltd. China Online Music Research Report 2007 Jan 2007 Page five

[4] the Internet Lab 2005 Wireless Music Market Research Report December 2005 Page seven

[5] Lai Mingfang, Zou Ren network music illegally, the International Federation of the Phonographic Industry decline China news published article 2007.7 edition four

[6] the king fly, America music industry prospect the evolution of the Sun Jiwei business (Chinese Business Review) second 2006 Page 32-33

[7]paulVerna,GlobalMusie:TurningIntoNewOPPortunities,eMarketer,2007.5PP.5 - 7.

[8] Xia Songbin, Liu Xufeng's mobile music value chain model of China's new communications in 2007 twenty-fourth Stage Page 14 
[9] ChinaVenture2007 China digital music industry investment analysis report October 2007 Page $1-3$

[10] the new technology and business room of the new technology and new business room for the development of communication information,the people's Posts and telecommunications business April 2007 http://Www.cnii.com.en/Zoo701os/ea4o9310.htm 